\title{
Labyrinthe
}

32 | 2009 (1)

Le petit théâtre intellectuel

\section{L'Éditorialiste/Le Blogueur}

\section{Guillaume Paugam}

\section{(2) OpenEdition}

\section{Journals}

Édition électronique

URL : http://journals.openedition.org/labyrinthe/3984

DOI : $10.4000 /$ labyrinthe.3984

ISSN : 1950-6031

Éditeur

Hermann

Édition imprimée

Date de publication : 19 juin 2009

Pagination : 33-36

ISBN : 978-2-7056-6885-3

\section{Référence électronique}

Guillaume Paugam, «L'Éditorialiste/Le Blogueur », Labyrinthe [En ligne], 32 | 2009 (1), mis en ligne le 01 février 2011, consulté le 05 mai 2019. URL : http://journals.openedition.org/labyrinthe/3984; DOI : 10.4000/labyrinthe.3984 


\section{L'ÉDITORIALISTE/LE BLOGUEUR}

Cruel face-à-face. Sur la scène, crépusculaire, l'homme se regarde, s'invite, se toise. Contemple longuement son reflet. Tour à tour fasciné, intrigué, horrifié. Cette image, mais mouvante, son double si sordidement exact, sa réplique morbide. Son image articulée. Et il se trouve laid. Atrocement laid. Désespérément. Le spectacle est insoutenable; la salle d'ailleurs a déserté à demi. Qu'importe, plus rien d'autre ne compte.

Mais non, ce n'est pas lui, ce reflet. Il n'est qu'un vis-à-vis, son autre tout autant que son miroir, quelqu'un doit surgir, un arbitre, un justicier, une bonne âme. N'importe qui. Et il saura les détromper, et il rompra l'envoûtement mystérieux. Il les séparera. Dénoncera publiquement cette incongrue gémellité, les démasquera, tranchera le nœud gordien de cette parfaite dissemblance. Ô délicieux soulagement... Mais il faudrait d'abord les reconnaître. Rendre l'Éditorialiste à sa dignité, le distinguer. Le rehausser de ses attributs, sa signature, sa gloriole, son nom. Lui faire justice, tout de même: «Reconnaissez-moi! » somme-t-il. Face à lui, ce Blogueur intrigant, impudent, frondeur. Malicieux, prétentieux, obstiné - mais pour qui se prend-il? Pour lui. Justement. Et il ne serait qu'un imposteur, s'il n'était pas le même: «Reconnaissez-moi... » supplie-t-il.

Mais l'Éditorialiste est un important, lui. Un patron de presse. Il connaît du monde; il a « réussi ». Stratège de haute volée, historien-futurologue et analyste multicarte (ascendant poète), sa plume compte. Ami des cercles, ceux des pouvoirs où il se commet, ceux du raisonnement où il se complaît, il pèse par ce qu'il est parce qu'il est parce qu'il pèse (etc.). Se gargarise d'être des puissants. Compte ceux qu'il tutoie. Parce qu'il leur dit ce qu'ils veulent croire? Que nenni! Parce que sa pensée est le phare qui éclaire, au loin, les rives de l'inconnu (il en est persuadé).

Qu'est le Blogueur face à lui ? Rien. Assurément. Et pourtant il le toise, l'infâme. Superbe en son genre. Et son sourire est ironique. Tissant obstinément sa propre toile, se gargarisant en son propre royaume: il vise l'aube d'un jour qu'il voudrait advenir; il est le futur, lui, quand l'Empire de l'Éditorialiste est en train de sombrer. Et c'est parce que cet 
ordre nouveau lui échappe que l'Éditorialiste ne peut pas le comprendre. Lui-même l'a prédit, mille fois écrit, le voit: c'est maintenant; c'est là ! Il n'est qu'à ouvrir les yeux. À l'en croire, le futur est déjà dépassé. Il faut voir plus loin, plus haut, plus vite. Sans cesse se réinventer (il le répète depuis si longtemps). Progressivement son audience croît. Et va croissant sa renommée; s'affermit sa courbe statistique. Il devient « influent ». Il pèse. Bientôt, il sera interviewé par les « vieux médias », ces anciennes idoles, sollicité pour une tribune, un article, un portrait. Il y pourra gloser sur lui-même. Ce qu'il est, ce qu'il pense, ce qu'il représente. Consécration.

Éditorialiste et Blogueur se visent. Peuvent-ils être si semblables et pour autant se détester? Quelque chose doit les séparer. L'Éditorialiste vitupère contre le Blogueur irresponsable, sujet à l'erreur, prompt critique et prêt à toutes les divulgations (secrets d'alcôves, récits d'initiés ou rumeurs invérifiées), le Blogueur raille cet Éditorialiste qui sermonne à la hâte, généralise plus que de raison et parle d'autorité - figure sentencieuse et vaguement paternaliste qui voudrait encore, vertige de l'asynchronie à son époque, réguler sa parole! Le Blogueur se construit un domaine spécifique dont il maîtrise les arcanes et vulgarise le fonctionnement, y attendant au tournant l'Éditorialiste présomptueux qui entendrait y pénétrer sans la qualification idoine - quitte à provoquer l'affrontement ô combien vain qui justifie son existence. Le voilà qui guette en sa niche l'approximation journalistique qui tout à la fois le désole et lui permet de se faire valoir. Peu à peu, il ne peut plus s'y tenir et s'entraîne lui-même à parler au-delà de sa propre expertise. Il généralise, extrapole et conjecture. Bientôt, il éditorialise. L'Éditorialiste saute le pas. Va s'encanailler sur cette toile - on ne saurait décemment la priver de ses vues sur la marche du monde, après tout. Prétend évangéliser. Ouvre un blog sur son nom. Les visiteurs affluent - qu'importe qu'ils soient en partie dubitatifs, l'unité de mesure est ici le «buzz », et le nombre de clics, jamais l'acquiescement. Le Blogueur s'indigne d'une concurrence forcément déloyale, persifle autant qu'il l'envie en secret cette notoriété internautique acquise frauduleusement. Crie à L'IMPOSTURE! (à force majuscules): l'Éditorialiste (à blog) n'est pas un vrai Blogueur (fût-il éditorialisant) ${ }^{1}$ !

1. «Une nouvelle blogosphère s'impose aujourd'hui, basée sur une audience de masse drainée par des noms devenus des marques, des marques dont la notoriété a été établie hors du web [...] Cette blogosphère-là me déplaît. Profondément. Viscéralement. » (http://novovision.fr/?Mesures-radicales- 
Reprend l'observation. Inlassablement. Un pas de côté, et Éditorialiste et Blogueur se demanderaient quelle est cette affinité secrète qui les fait disserter l'un sur l'autre, s'observer jusqu'à la lie, se mesurer sans cesse, se fasciner ad nauseam et rejouer en pantomime l'affrontement soixante-huitard des « intellectuels » post-mai - «penseur universel » contre « intellectuel spécifique »-qui, aussi différents qu'ils voulurent se présenter, se retrouvaient en permanence et du même côté aux mêmes combats. Le privilège de l'Éditorialiste que l'existence même du Blogueur vient menacer? Peut-être sa plume, la plus à distance de l'« objectivité journalistique », que vient directement concurrencer le « je » revendiqué du Blogueur (dépendant tout autant - quoique absolument déconnecté - du labeur de terrain: le travail de reportage généreusement laissé à la piétaille journalistique). L'attribut de l'Éditorialiste que le Blogueur n'a de cesse de jalouser? Peut-être l'« influence » qu'il voudrait revendiquer, le poids fantasmé de ses prises de positions - un certain écho surgi des cimes des médias historiques qu'il vient singer en petit sur son monticule virtuel. Mais effectuer un tel pas demeure impossible. Absorbé dans sa contemplation de son étrange autre, de son inquiétant même, de la laideur fascinante qu'il lui renvoie, l'Éditorialiste/le Blogueur perpétue le charme qui maintient l'un l'autre attaché à distance.

Sur la scène, la pénombre s'est installée. La salle est maintenant complètement vide. Personne n'est venu les délivrer. À force de ne pouvoir regarder ailleurs, Éditorialiste et Blogueur se sont isolés dans une contemplation qui, en propre, ne regarde qu'eux. Un instant encore, admirons comme leurs silhouettes jadis distinctes s'agglomèrent si parfaitement dans le noir...

G. P.

contre-la-derive [consulté le 17 février 2009]); voir également la critique des «faux-blogueurs »: «Morandini et Birenbaum, blogueurs? Oui, ils tiennent un blog, mais ce n'est qu'une facette de leur activité éditorialo-médiatique [...]. Un journaliste-éditeur qui tient un blog est avant tout un journaliste éditeur, de même qu'un politique blogueur est d'abord un politique qui parle de politique. » (http://www.authueil.org/?2007/04/18/380-faux-blogueurs [consulté le 17 février 2009]). 


\section{Webographie, références, lectures}

I. Animé par un ancien journaliste, le blog Novövision (http://novovision.fr) ainsi que son outil de veille associé (http://delicious.com/narvic) se révèle un instrument précieux d'analyse des mutations du paysage journalistique face à la concurrence de l'information en ligne. La recherche porte sur le modèle éditorial (thème du « journalisme de liens ») et non sur le modèle économique (aucune initiative des initiatives proposées ne pouvant prétendre à la rentabilité).

II. Le blog «Internet et opinion » propose une étude sur « Les médias en ligne et leurs politiques [sic] de blogs » instructive notamment quant à l'offre blog des «médias historiques » au cours de leur passage en ligne et donc la conversion, plus ou moins volontaire, des éditorialistes aux joies du blogging; voir: http://internetetopinion.wordpress.com/2008/11/30/ les-medias-en-ligne-et-leurs-politiques-de-blogs/[consulté le 17 février 2009])

III. Un bel exemple de querelle vit s'affronter l'emblématique blogueur Versac (Nicolas Vanbremeersch, qui a depuis fermé son blog) et l'éditorialiste Jean-Michel Aphatie (éditorialiste officiant sur la station de radio RTL et sur Canal +, blogueur sur le portail de ladite station depuis 2005); un billet de Narvic, à l'origine du conflit, est également celui qui le résume le mieux. Voir: http://novovision.fr/?Mon-blog-prefere-et-mon-blog; http://www. versac.net/2008/07/journaliste-blo.html et http://blogs.rtl.fr/aphatie/index. php/post/2008/07/04/Reponse-a-Versac [consultés le 17 février 2009].

IV. «Le peuple des connecteurs » (http://blog.tcrouzet.com/) est un exemple de blog mué par l'idée d'une révolution des modes de pensée due à l'influence technico-sociale des réseaux sur notre conception du monde ( « pensée horizontale » plutôt que « verticale »), vision que l'auteur - qui se présente lui-même comme « expert en rien »-alternativement diagnostique comme inévitable, accompagne dans son mouvement ou encore appelle de ses vœux. La prééminence à la fois présente et à venir de l'internet sur la presse n'est que l'un des nombreux effets de cette influence inexorable (voir, entre autres exemples: http://blog.tcrouzet.com/2008/02/13/c'estquoi-un-bon-journaliste/[consulté le 17 février 2009]). 